\title{
An evaluation of CORDEX regional climate models in simulating precipitation over Southern Africa
}

\author{
Mxolisi E. Shongwe, ${ }^{1,2 *}$ Chris Lennard, ${ }^{3}$ Brant Liebmann, ${ }^{4}$ Evangelia-Anna Kalognomou, ${ }^{5}$ Lucky Ntsangwane \\ and Izidine Pinto ${ }^{2}$ \\ I South African Weather Service, Private Bag X097, Pretoria, South Africa \\ ${ }^{2}$ University of Pretoria, South Africa \\ ${ }^{3}$ Climate Systems Analysis Group, University of Cape Town, 7945, South Africa \\ ${ }^{4}$ NOAA-CIRES Climate Diagnostics Center, Boulder, CO, USA \\ ${ }^{5}$ Laboratory of Heat Transfer and Environmental Engineering, Aristotle University, Thessaloniki, Greece
}

*Correspondence to:

M. E. Shongwe, South African Weather Service, Private Bag X097, Pretoria, South Africa. E-mail: mxolisi.shongwe @weathersa.co.za
Received: 17 January 2014 Revised: I September 2014 Accepted: 5 September 2014

\begin{abstract}
This article evaluates the ability of the Coordinated Regional Downscaling Experiment (CORDEX) regional climate models (RCMs) in simulating monthly rainfall variation during the austral summer half year (October to March) over southern Africa, the timing of the rainy season and the relative frequencies of rainfall events of varying intensities. The phasing and amplitude of monthly rainfall evolution and the spatial progression of the wet season onset are well simulated by the models. Notwithstanding some systematic biases in a few models, the simulated onset and end of the rainy season and their interannual variability are highly correlated with those computed from the reference data. The strongest agreements between the reference and modelled precipitation patterns are found north of about $20^{\circ} \mathrm{S}$ in the vicinity of the Inter Tropical Convergence Zone. A majority of the RCMs adequately capture the reference precipitation probability density functions, with a few showing a bias towards excessive light rainfall events.
\end{abstract}

Keywords: CORDEX - Africa; regional climate model evaluation; rainfall characteristics

\section{Introduction}

As the Earth's climate continues to change, the characteristics of regional precipitation and extreme events may change without necessarily being reflected in seasonal totals (Seneviratne et al., 2012; Trenberth et al., 2003). For example, changes in wet season timing may not affect calendar season totals, and changes in wet season duration may be balanced by changes in the intensity or frequency of daily precipitation during that season. Changes in the character of precipitation have important implications for a number of climate-sensitive sectors such as agriculture, forestry, water resources, ecosystem services and disaster risk management. For instance, steady, soaking, moderate rains are generally better for agriculture than the same amount of rainfall over a short period, which may result in rapid runoff and flash flooding, leaving the deeper soil layers dry. The timing and duration of the rainy season inter alia determine the planting dates and the selection of crop types. Despite their obvious importance, however, the changes in rainfall characteristics are seldom analysed in observations (e.g. Reason et al., 2005) or regional-scale climate simulations in Africa.

Changes in the scale and shape of the rainfall distribution, which may alter tail probabilities, affect the physical and natural systems more than changes in its central tendency (Easterling et al., 2000). An evaluation of the ability of climate models in simulating the entire precipitation probability distribution at regional scales (e.g. Perkins et al., 2007) while clearly warranted has not yet been done for southern Africa. The present study attempts to address these issues by assessing the ability of the Coordinated Regional Downscaling Experiment (CORDEX) regional climate models (RCMs) in capturing monthly rainfall evolution, selected rainfall characteristics and the observed rainfall probability density functions (PDFs) in their control simulations of daily rainfall events over predefined rainfall regions (Shongwe et al., 2009) in Africa south of $10^{\circ} \mathrm{S}$.

Since the launch of the CORDEX Africa programme (Jones et al., 2011), a few studies have evaluated the RCM performance over parts of the continent, including southern Africa (Nikulin et al., 2012; Kalognomou et al., 2013). Monthly and seasonal data have been used to assess the RCM's ability to simulate the main features of seasonal mean rainfall distribution and the rainfall annual cycle. Notwithstanding biases in some regions and seasons, such as a wet bias (dry bias) close to Lesotho (over northern Mozambique) during austral summer months, the models were found to adequately simulate precipitation patterns (Kalognomou et al., 2013). However, monthly and seasonal averages or totals can conceal systematic biases in the simulated climate (e.g. Tadross et al., 2005). Also, given that cumulative effects of weather events on daily time scales have a direct impact on natural systems and 
human activities, an assessment of model ability to simulate the characteristics of daily rainfall events is clearly valuable.

Over southern Africa, seasonal rainfall characteristics have become a subject of interest in recent years/decades, particularly their relevance for agriculture (Tadross et al., 2005, 2009). Tadross et al. (2005), using observation-based data up to 1997 , showed that the mean onset occurs earlier (September or October) over eastern South Africa and later (November to December) over northern Mozambique and Botswana. A trend towards a later onset was found over northeastern South Africa. Using seven Coupled Model Intercomparison Project Phase 3 (CMIP 3) global climate models statistically downscaled to station data, Tadross et al. (2009) projected a reduction in mid twenty-first century (2046-2065) austral spring precipitation, and an increase in the autumn, suggesting a shift of the rainy season to later dates over southern Africa north of about $20^{\circ} \mathrm{S}$. No attempt was made to quantify the uncertainty associated with the downscaling procedure. The CORDEX Africa programme produces large volumes of data necessary to provide future projections of high-frequency precipitation statistics and a quantification of the inherent uncertainties. This paper provides the necessary foundation for such analyses by assessing the models' ability to replicate some rainfall statistics in their control simulations.

\section{Data and methodology}

Monthly and daily rainfall simulated by 10 CORDEX RCMs over the common 17-year period (1991-2007), driven by the ERA-Interim reanalysis (Simmons et al., 2006), are used. The RCMs include: (1) the Université du Québec à Montréal fifth-generation Canadian Regional Climate Model (CRCM5), (2) the Universidad de Cantabria Weather Research and Forecasting Model, version 3.1.1 (WRF3.1.1), (3) the Sveriges Meteorologiska och Hydrologiska institut (SMHI) Rossby Centre Regional Atmospheric Climate Model, version 3.5 (RCA3.5), (4) the Max Planck Institute Regional Model (REMO), (5) the Consortium for Small-scale Modelling (COSMO) Climate Limited-Area Model, version 4.8 (CCLM4.8), (6) the Centre National de Recherches Météorologiques Action de Recherche Petite Echelle Grande Echelle, version 5.1 (ARPEGE5.1), (7) the Abdus Salam International Centre for Theoretical Physics RCM, version 3 (RegCM3), (8) the University of Cape Town Providing Regional Climates for Impacts Studies (PRECIS), (9) the Danmarks Meteorologiske Institut HIRHAM, version 5 (HIRHAM5; the HIRHAM5 has days with missing data and has been omitted in the analysis of onset and withdrawal of the rainy season) and the Koninklijk Nederlands Meteorologisch Instituut Regional Atmospheric Climate Model, version 2.2b (RACMO2.2b). The RCM setup details and relevant references are presented in Nikulin et al. (2012) and Kalognomou et al. (2013).

Owing to the dearth and/or inaccessibility of observational data over much of the study area, the ERA-Interim reanalysis is used as the reference data set to assess model performance. Throughout this paper, reference data refer to the ERA-Interim precipitation. Given the uncertainty associated with observation-based data sets (Kalognomou et al., 2013; Sylla et al., 2013), the Global Precipitation Climatology Project (GPCP; Huffman et al., 2009) data, which are available from 1997, are also used for comparison.

The homogeneous rainfall regions over southern Africa defined by Shongwe et al. (2009) are adopted in this study. CORDEX simulation of monthly spatially averaged precipitation is assessed using Taylor diagrams (Taylor, 2001), which graphically synthesize the degree of correspondence between RCMs and the reference data in terms of the phase and amplitude of their evolution, measured by Pearson correlation coefficients, the centred root-mean-square error (RMSE) and a comparison of their variances. Taylor diagrams are widely used to evaluate the multiple aspects of complex models and gauging the relative skill of many different models (e.g. Kalognomou et al., 2013).

Onset and cessation of the wet season is defined for each region in Figure 1, assuming spatial coherence of the timing across the individual regions, from anomalous precipitation accumulation in a given day $[A$ (day)] as

$$
A(\text { day })=\sum_{n=1}^{\text {day }} R(n)-\bar{R}
$$

where $R(n)$ is the daily precipitation and $\bar{R}$ is the long-term annual daily mean (Liebmann et al., 2007; Rauscher et al., 2007). The calculation started on 1 July (climatologically, the driest month; see Figure 2 of Shongwe et al., 2009). The onset of the rainy season is defined as the date on which the curve reaches a minimum, since after that date precipitation exceeds the annual daily climatology and before that date precipitation is less than the annual climatology. Prior to onset, there are often brief periods of precipitation causing the curve to move upward, but these are considered 'false' onsets, because the curve ultimately falls to its absolute minimum for the year. Similarly, cessation is defined as the date on which the curve reaches the maximum, since after that date precipitation is less than climatology (e.g. Figure 2 of Liebmann et al., 2007). Pearson correlation coefficients and RMSE are computed between the simulated and reference onset and cessation dates. Statistical significance of the computed correlation is assessed using a parametric Student's $t$-test.

Regional PDFs are constructed for the reference data sets and CORDEX RCMs by considering all the grid points falling within a region, omitting daily precipitation values $<0.1 \mathrm{~mm}$ day $^{-1}$ at any given grid. The PDFs are compared visually. 


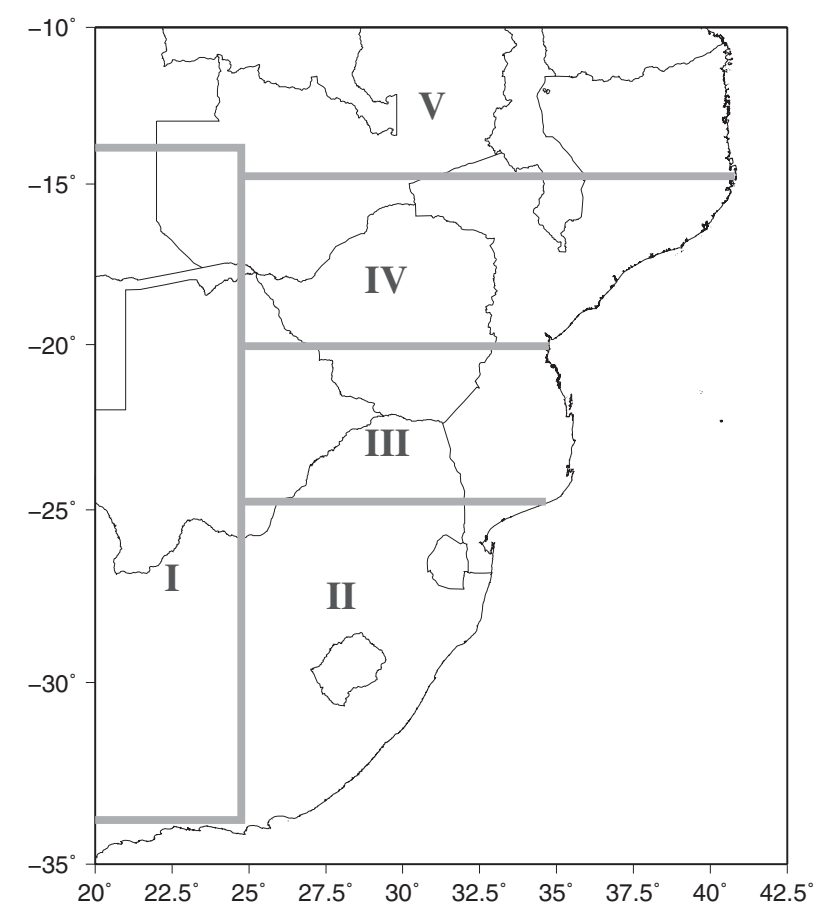

Figure I. Location map of the Southern Africa homogeneous climate regions defined by Shongwe et al. (2009).

\section{Simulation of monthly precipitation}

There are notable spatial inhomogeneities and intermodel differences in simulating the phasing and amplitude of monthly rainfall evolution (Figure 2). Relative to the south (Figure 2(a)-(c)), the simulated monthly precipitation to the north of about $20^{\circ} \mathrm{S}$ (Regions IV and V) is in better agreement with the reference data (Figure 2(d) and (e)). Almost all RCMs attain correlation scores $>0.5$, centred RMS differences (the curved contours in each plot) $\leq 2 \mathrm{~mm} \mathrm{day}^{-1}$ and have their intermonthly standard deviation close to the reference data in Regions IV and V. To the south (Regions I, II and III), the pattern correlation is lower $(\leq 0.6)$ in most RCMs, but statistically significant (from re-randomization tests, not shown), indicating that the downscaled monthly precipitation can still provide useful information in these regions.

APERGE5.1 stands out as the RCM with the best agreement with the reference data. This model's pattern correlation exceeds 0.8 everywhere, and the RMS differences between this model's downscaled precipitation and the ERA-Interim reanalysis are the smallest. The WRF3.1.1 model, albeit comparable with the majority of the RCMs in its ability to simulate the phase of the monthly rainfall evolution, has the largest amplitude of precipitation variation.

\section{Seasonal rainfall onset and withdrawal}

The observed rainfall annual cycle plots for each climatic region are shown in Figure 2 of Shongwe et al. (2009). The rainy season begins first in the southeast and progresses northward. Earlier onset over eastern South Africa (Region II) is associated with moisture advection from the warm Agulhas system and instabilities induced by mid-latitude disturbances (Tyson and Preston-Whyte, 2000). The spatial progression of the regional rainfall onset in the RCMs is broadly consistent with the reference and the GPCP data, which often present similar estimates of the rainy season timing for the common period 1997/1998-2007/2008, a notable exception being the 2002/2003 season. In ERA-Interim, the mean (median) rainfall onset date in Region II is 22 October (18 October), with an interannual standard deviation $(\sigma)$ of 15 days. In the GPCP data, the mean onset date and $\sigma$ for eastern South Africa (i.e. Region II) are 23 October and 17 days. Albeit not statistically significant, the trend towards later onset of 1 day year $^{-1}$ in the GPCP data over eastern South Africa is consistent with Tadross et al. (2005) and the broadly held notion that in parts of southern Africa, the start of the rainy season has shifted to later dates in recent years/decades. In the ERA-Interim, a weaker delayed onset $\left(4\right.$ days decade $\left.{ }^{-1}\right)$ is only found in the late twentieth century.

Most of the CORDEX RCMs adequately capture the mean rainfall onset in Region II, falling within \pm 7 days of the reference data (Figure 3(b)). To the southwest (Region I), the mean start of the rainy season occurs around 8 November and 16 November in the ERA-Interim and GPCP reference data sets, respectively. A trend towards a delayed onset $(3 \pm 2$ days year $^{-1}$ ) is found during the last decade of the twentieth century. With reference to ERA-Interim, RegCM3 has the overall early mean onset bias of $\approx 14$ days, while the onset in the CCLM4.8 is delayed by about 11 days. Except these two and the RCA35, the mean onset dates in the rest of the RCMs fall within a 7 day margin from the ERA-Interim estimate in Region I (Figure 3(a)). To the north, where moisture recycling ratios are relatively higher during austral summer months (Trenberth, 1999), the seasonal rainfall onset occurs slightly later, around 12 (09), 19 (14) and 11 (12) November in Regions III, IV and V in the ERA-Interim (GPCP) data, respectively, with a relatively low interannual variability (Figure 3(c)-(e)). In Region III, all the RCMs except the RegCM3 have onset dates between 07 and 19 November (Figure 3(c)). In the RegCM3, the mean rainfall onset occurs around 25 October. Over northern Zimbabwe and central Mozambique (Region IV), the onset bias is low, with the CCLM4.8 showing a slight late bias (Figure 3(d)). The onset bias is similarly quite low over the northern-most region (Region V) will almost all RCMs simulating mean onset dates within \pm 7 days of 11 November.

Correlations between reference and simulated onset dates are shown in Table 1. It is evident from the table that the RCMs capture the interannual variability of the rainfall onset reasonably well. In particular, the ARPEGE5.1 attains statistically significant correlations and lowest RMSE almost everywhere. There are a few cases when the RCM simulated onset dates are out of 
(a)

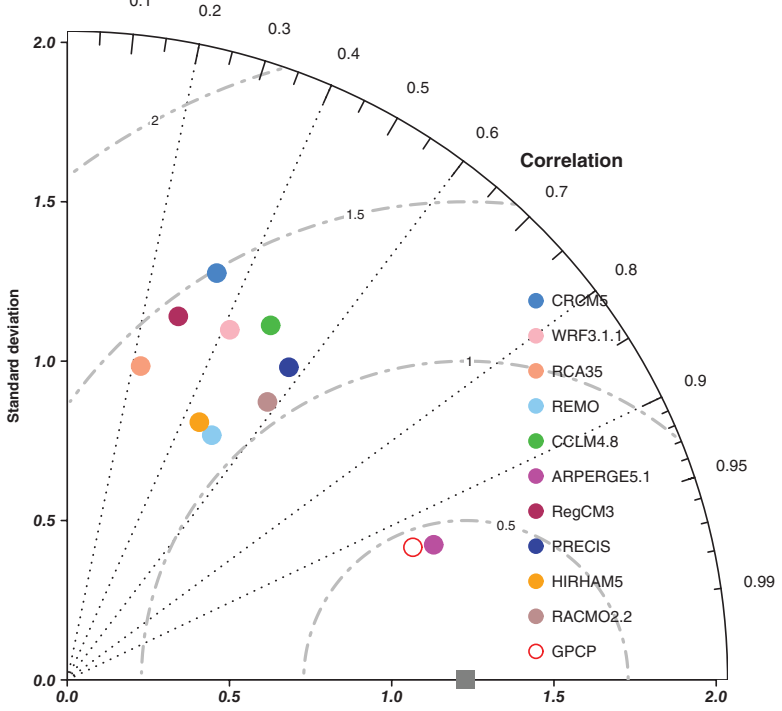

(c)

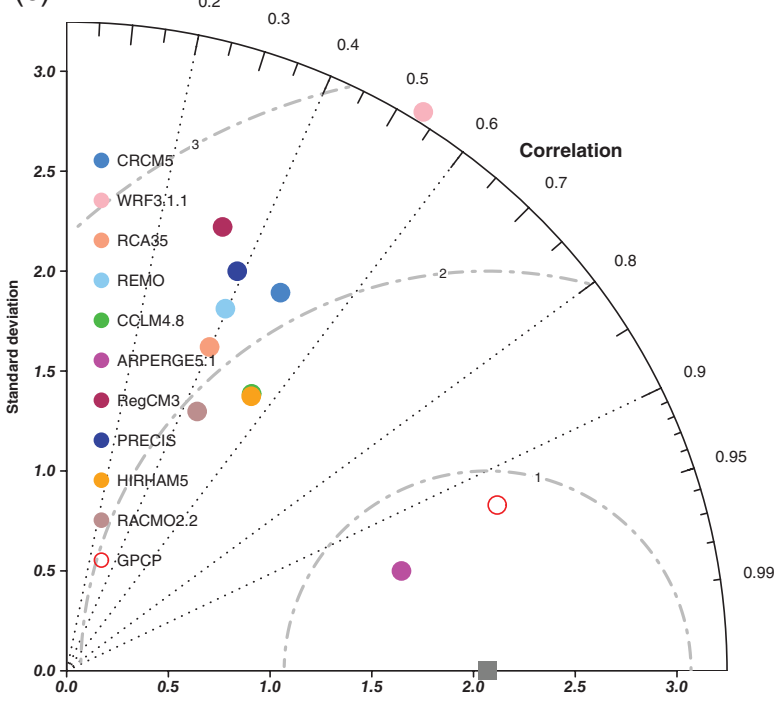

(b)

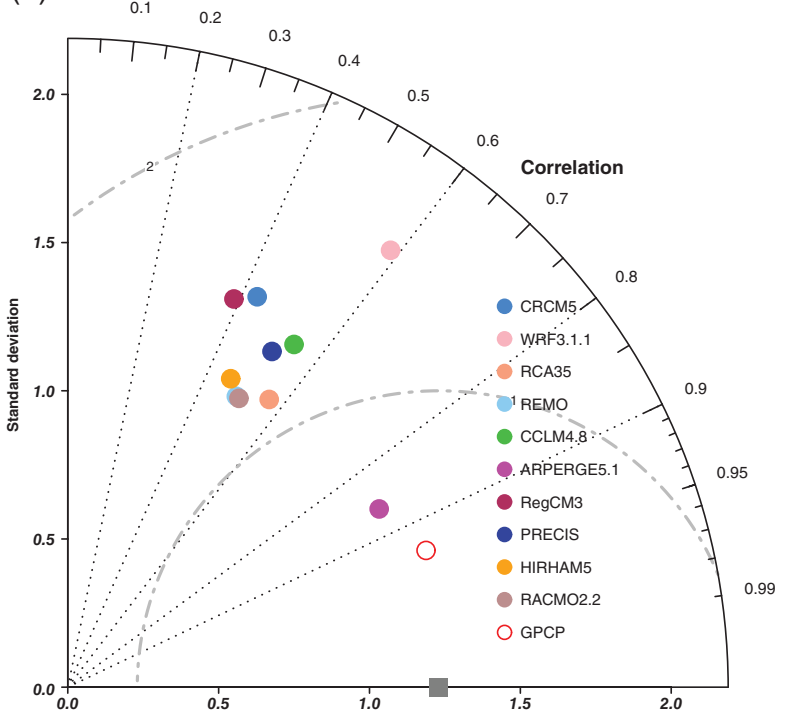

(d)

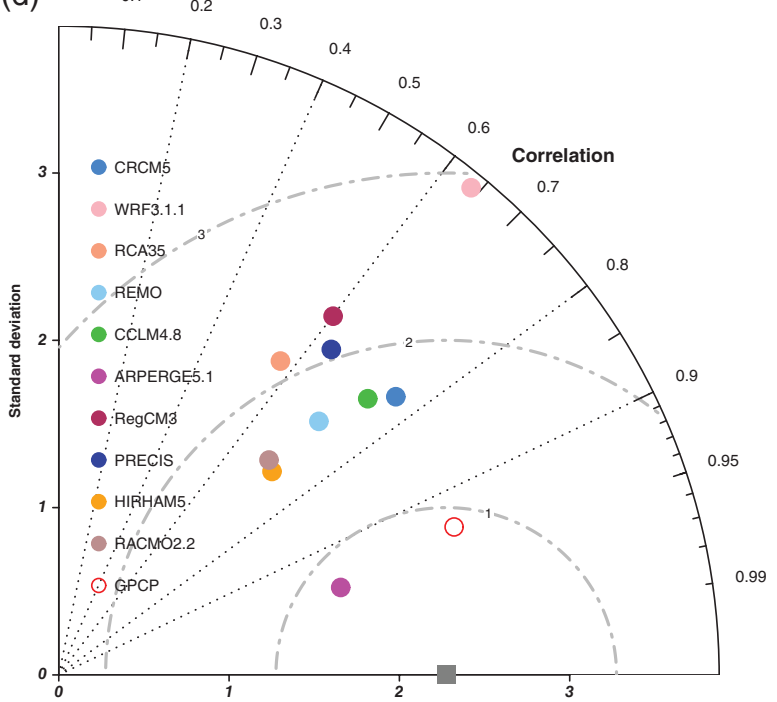

(e)

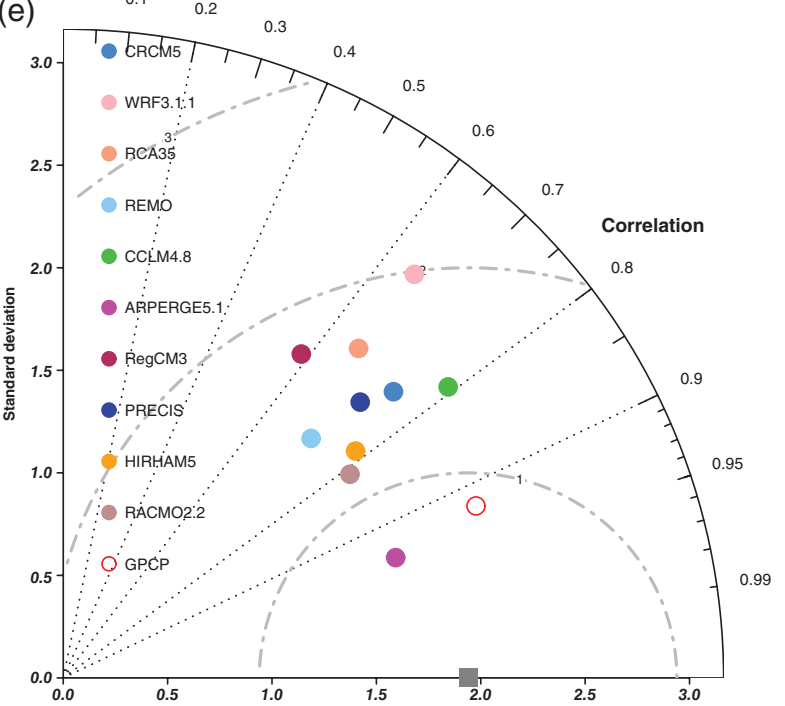

Figure 2. Taylor diagrams for area-averaged monthly precipitation in Regions (a) I, (b) II, (c) III, (d) IV and (e) V shown in Figure I. The reference (ERA-Interim) data are shown by the grey square along the horizontal axis. The individual RCMs are shown by the solid circles and the GPCP by the open circle. The radial coordinate shows the standard deviation. The azimuthal axis shows the correlation between the RCMs and the reference data. The centred root-mean square error is indicated by the dashed grey semi-circles about the reference point. 


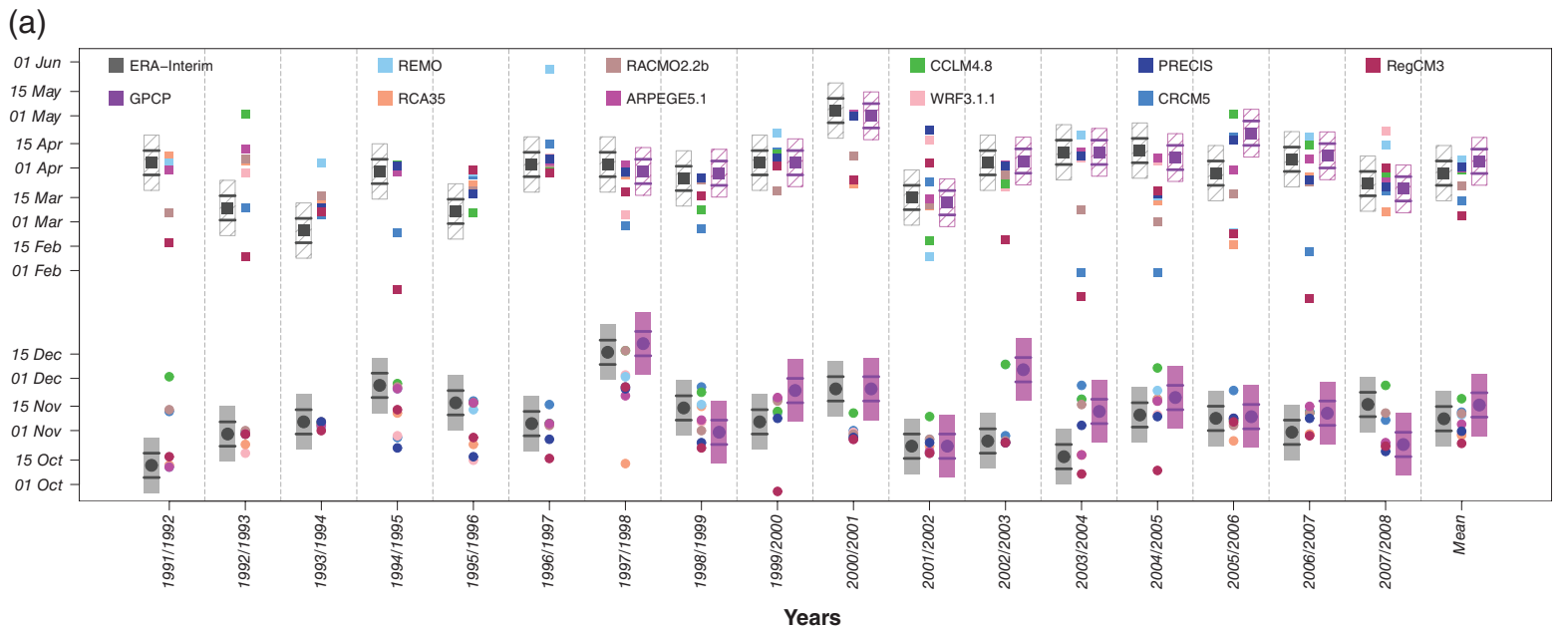

(b)
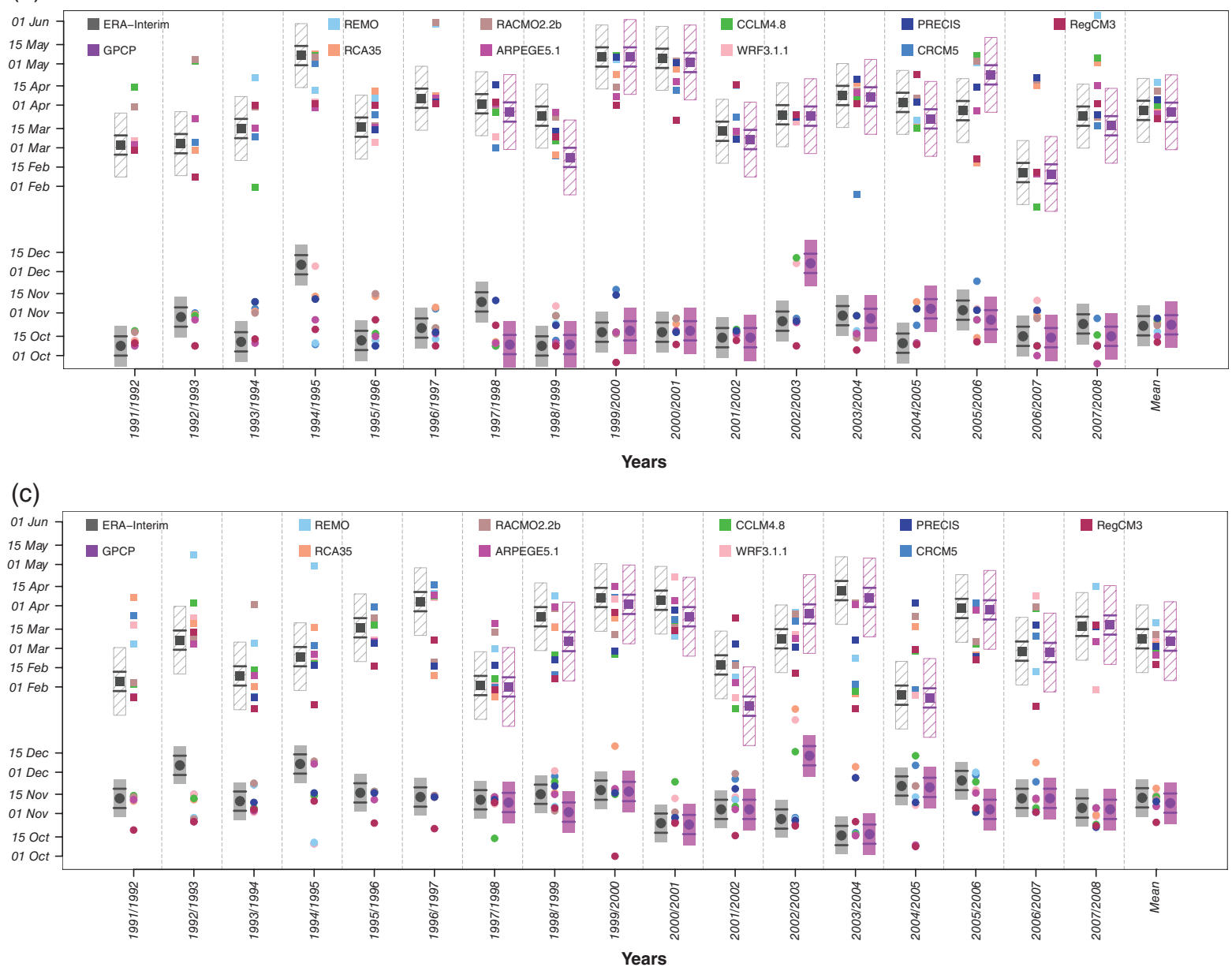

Figure 3. ERA-Interim (grey rectangles), GPCP from 1997/I998 (orchid rectangles) and CORDEX-simulated (individual points) interannual onset (solid circles) and cessation (solid squares) dates of the wet season for Regions (a) I, (b) II, (c) III, (d) IV and (e) $\mathrm{V}$. In each figure, the onset (cessation) date is plotted at the lower (upper) ordinate running from 0I October to 15 December ( 0 I February to $0 \mathrm{I}$ June). For the reference plots, the rectangles extend to $\pm \mathrm{l} \sigma$ of interannual variability from the estimated date, while the line segments within each rectangle extend to \pm 7 days.

phase with the reference data (e.g. CRCM5 and REMO in Region II, RCA3.5 in Region III and WRF3.1.1 in Region IV). The weak correlation between the GPCP and ERA-Interim in Regions I and II demonstrates how different observational-based data sets may disagree on their representation of precipitation characteristics (e.g. Kalognomou et al., 2013).
In the reference data, rainfall withdrawal does not show any notable spatial migration. Almost everywhere, except in Region III, the mean end date occurs between 28 March and 05 April (27 March and 06 April) in ERA-Interim (GPCP). In Region III, which has long been known to have strong ENSO teleconnections (Ropelewski and Halpert, 1987; Rocha 
(d)

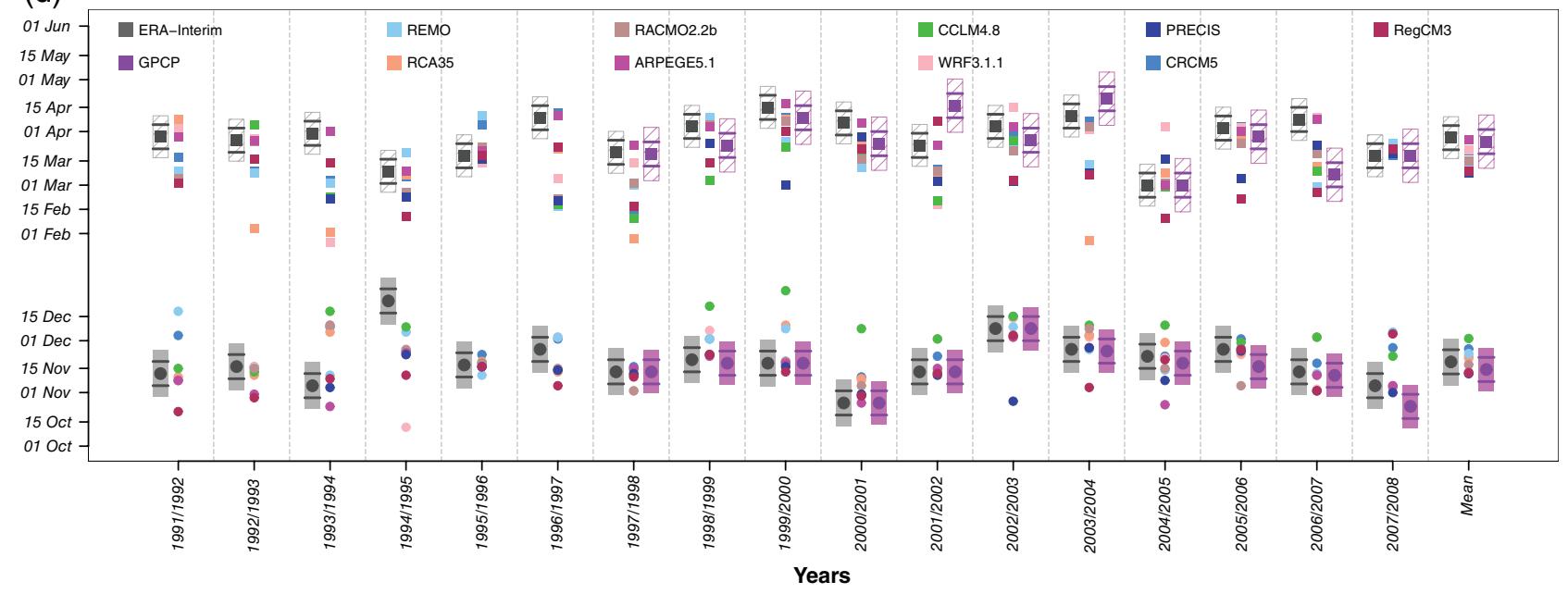

(e)

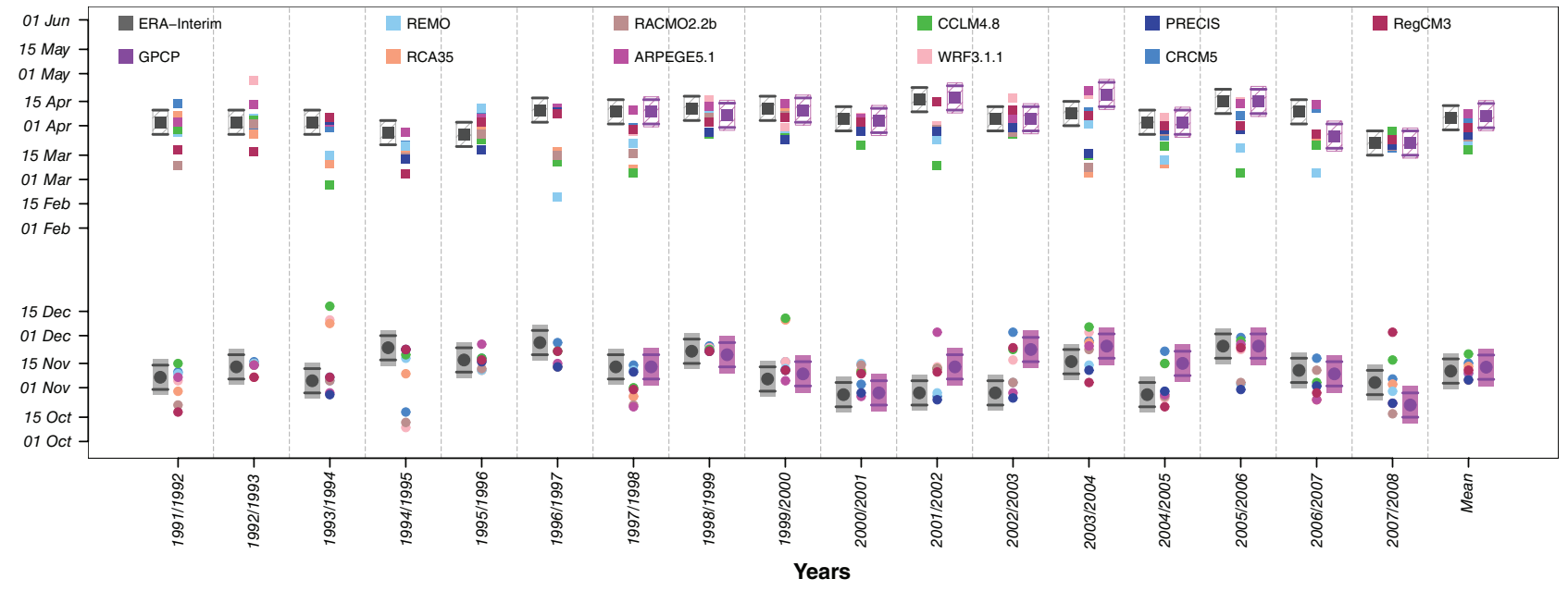

Figure 3. continued

Table I. Correlation between the RCMs and the reference ERA-Interim onset dates.

\begin{tabular}{|c|c|c|c|c|c|}
\hline CM & I & gion II & Region III & Region IV & Regic \\
\hline & & & & & \\
\hline & & & & & \\
\hline & & & & & \\
\hline & & & & & \\
\hline 5 & & & & 3) & *** (7) \\
\hline , & $0.56^{* *}$ & & & & \\
\hline 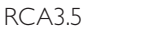 & 0 & 8 & $-0.23(3 \mathrm{I})$ & $39(14)$ & $.13(16)$ \\
\hline $\mathrm{eg} C \mathrm{CM}$ & $\mathbf{0 . 6 3 ^ { * * }}(13)$ & $2(14)$ & $0.12(23)$ & $0.26(15)$ & $0.21(15)$ \\
\hline EMO & 8 & $-0.09(18)$ & $\mathbf{0 . 6 9 * *}(10)$ & $0.50^{* *}(13)$ & $\mathbf{0 . 6 2 ^ { * * * } ( 9 )}$ \\
\hline RF3.I.I & $\mathbf{0 . 6 7} \mathbf{7}^{* *}(12)$ & $0.46(17)$ & $\mathbf{0 . 5 3}^{* *}(12)$ & $-0.18(22)$ & $0.06(18)$ \\
\hline
\end{tabular}

The RMSE (days) for each RCM is shown in brackets. Correlations that are significant at the $10 \%(5 \%)$ level are in bold (shown by two asterisks).

and Simmonds, 1997), the mean cessation, which occurs around 08 and 06 March in the reference data and GPCP, is influenced by six early cessation seasons (1991/1992, 1993/1994, 1994/1995, 1997/1998, 2001/2002 and 2004/2005). In these extreme years, four (in bold font) of which coincided with a warm ENSO phase, the seasonal rainfall ends either late in
January (e.g. 2004/2005) or early to mid-February. Statistically significant correlations (at the 10\% level) have been found between ENSO and early rainfall cessation over a number of stations in Zimbabwe, southern Mozambique and Malawi (Tadross et al., 2009). Noteworthy, the southeastern regions (Regions II and III) have a high interannual variability $(\sigma \geq 25$ days) of the rainfall withdrawal (Figure 3(b) and (c)).

The pattern of rainfall cessation in the RCMs closely resembles that of the reference data, with some models showing an excellent agreement even during the unusual years. In Region I, all except two of the RCMs (RegCM3 and CRCM5) have end dates within \pm 7 days of the reference data. In RegCM3, the mean end date occurs quite early (04 March), while in CRCM5, the average cessation occurs around 13 March, 16 days earlier than in ERA-Interim. Over eastern South Africa (Region II), the largest biases are found in REMO and RACMO2.2 where the end of the rainy season is delayed by 21 and 14 days, respectively. In almost all the RCMs, the cessation dates vary greatly from year to year, in close agreement with the reference data (Figure 3(b)). In Region III, early withdrawals in the 
Table 2. Correlation between the RCMs and the reference ERA-Interim cessation dates.

\begin{tabular}{|c|c|c|c|c|c|}
\hline $\mathrm{RCM}$ & eg & Regi & Regic & Regio & $\operatorname{Re}$ \\
\hline РP & (7) & $\mathbf{0 . 8 8}^{* *}(12)$ & & $\mathbf{0 . 5 4}(13)$ & \\
\hline RPEGE5.I & $\mathbf{0 . 8 2 ^ { * * }}(9)$ & $\mathbf{0 . 7 9 ^ { * * } ( 1 4 )}$ & $\mathbf{0 . 8 4}^{* *}(9)$ & $\mathbf{0 . 7 8}^{* *}(8)$ & $\mathbf{0 . 8} \mathbf{I}^{* *}$ \\
\hline CLM4.8 & $\mathbf{0 . 4 6}(19)$ & $\mathbf{0 . 6 0 ^ { * * }}(9)$ & $0.36(28)$ & $0.23(16)$ & $-0.29(14$ \\
\hline RCM5 & $-0.09(29)$ & $0.33(31)$ & & $\mathbf{0 . 6 5 *}(12)$ & $\mathbf{0 . 5 5 ^ { * * }}$ \\
\hline PRECIS & $\mathbf{0 . 5 6 * *}(14)$ & $\mathbf{0 . 4 4}(21)$ & $0.06(3 \mathrm{I})$ & $0.04(17)$ & 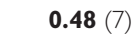 \\
\hline BACMO & & $\mathbf{0 . 7 2}^{* *}(15)$ & & & - \\
\hline CA3.5 & $0.20(18)$ & $16(24)$ & & & (1 \\
\hline & & $\mathbf{0 . 5 \mathbf { 0 } ^ { * * }}(22)$ & $\mathbf{0 . 5 3}^{* *}(25)$ & 5) & *** \\
\hline REMO & $0.25(27)$ & $\mathbf{0 . 6} \mathbf{I}^{\text {*** }}(18)$ & $0.16(38)$ & $\mathbf{0 . 6 4} \mathbf{4}^{* *}(19)$ & $-0.19(1$ \\
\hline WRF3.I.I & $\mathbf{0 . 4 7}(17)$ & $0.38(25)$ & $\mathbf{0 . 8 2 * *}(17)$ & $0.37(21)$ & 0.32 \\
\hline
\end{tabular}

The RMSE (days) for each RCM is shown in brackets. Correlations that are significant at the 10\% (5\%) level are in bold (shown by two asterisks).

RegCM3 occur often, which results in an average negative bias of 18 days. Further north (Region IV), where the ability to simulate monthly rainfall is highest, negative biases in RCM end dates in excess of 18 days are found in PRECIS, CCLM4.8, RCA3.5 and RegCM3. Over the north-most Region V, disagreements between average reference and models' end dates still persist (Figure 3(e)).
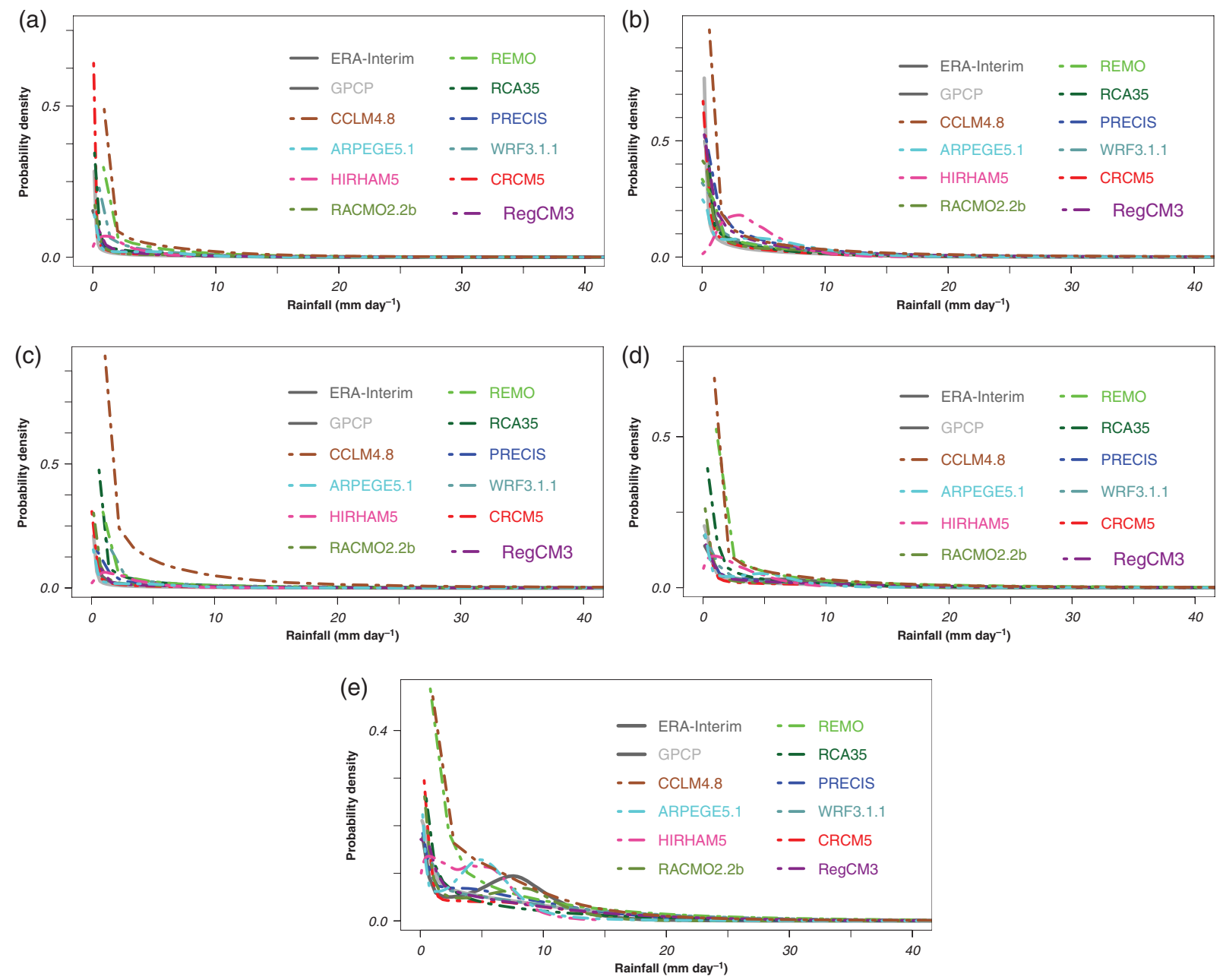

Figure 4. Reference (solid lines) and CORDEX (dot-dashed lines) precipitation probability density functions for Regions (a) I, (b) II, (c) III, (d) IV and (e) V. 
low-tail probabilities comparable with the reference data. In most cases, the CCLM4.8, and in some cases, the REMO overestimate the probability of light rainfall by about 2-3 times. The RACMO2.2, the ARPEGE5.1 and the HIRHAM5 get very close to capturing the secondary peak probabilities located around 5-10 $\mathrm{mm}$ day $^{-1}$ in the ERA-Interim data in Region V.

\section{Summary and conclusions}

The present study has enabled us to get to grips with how well the CORDEX RCMs simulate monthly rainfall amounts and some regional rainfall characteristics over southern Africa. The models have been evaluated against the ERA-Interim reanalysis, whilst the GPCP data have been used for comparison. In simulating monthly rainfall variability, the overall performance of the RCMs is good, particularly to the north of the study domain. The stretched grid ARPEGE5.1 appears to the best overall performer, in qualitative agreement with Kalognomou et al. (2013), where the individual RCM setups are presented. This RCM's correlation with the ERA-Interim data is highest almost everywhere in southern Africa and the biases are least. No attempt is made in this paper to identify the model physics and dynamics responsible for the differences in RCM performance. Other aspects of the simulated precipitation that are of practical significance such as rainy season timing and the relative frequencies of a spectrum of rainfall intensities have also been analysed. The spatial migration of the seasonal rainfall onset is well captured by the RCMs. The reference and simulated average onset and withdrawal dates are within a few days of each other, and the interannual variability is captured by the RCMs, a few notable biases notwithstanding. A visual comparison of the reference and simulated PDFs shows that a majority of the models do quite well in representing the probabilities of certain rainfall events.

There are prospects for the CORDEX RCMs to provide usable information on regional monthly precipitation, rainfall characteristics and probabilities of events of differing intensities over southern Africa, and their likely future changes, for climate change impacts assessments where impacts are related to precipitation. The uncertainties associated with the modelling process from the driving climate to impacts are yet to be quantified. One of the goals for future work is to investigate and compare the physical mechanisms underlying rainfall variability and changes in rainfall character in observations and in the models.

\section{Acknowledgements}

Review comments by Dr. Rachel James and two anonymous reviewers are greatly appreciated. This paper is a contribution of the Southern African Analysis group to the CORDEX-Africa programme. The CORDEX-Africa programme was supported by the Global Change System for Analysis, Research, and Training (START) through the Climate Systems Analysis Group of the University of Cape Town. Support from the World
Climate Research Program (WCRP), the Climate and Development Knowledge Network (CDKN), the International Centre for Theoretical Physics (ICTP), the Swedish Meteorological and Hydrological Institute (SMHI) and the European Union Seventh Framework Programme is gratefully acknowledged. Special thanks to the modelling groups contributing to the CORDEX-Africa program and to Grigory Nikulin from SMHI for post-processing the data to a common grid, data format and domain size to enable direct comparison in the analyses.

\section{References}

Easterling DR, Meehl GA, Parmesan C, Changnon SA, Karl TR, Mearns LO. 2000. Climate extremes: observations, modeling, and impacts. Science 289: 2068-2074.

Huffman GJ, Adler RF, Bolvin DT, Gu G. 2009. Improving the global precipitation record: GPCP version 2.1. Geophysical Research Letters 36, doi: 10.1029/2009GL04000.

Jones C, Giorgi F, Asrar G. 2011. The Coordinated Regional Downscaling Experiment (CORDEX). An international downscaling link to CMIP5. Clivar Exchanges 16: 34-40.

Kalognomou E-A, Lennard C, Shongwe M, Pinto I, Favre A, Kent M, Hewitson B, Dosio A, Nikulin G, Panitz H-J, Büchner M. 2013. A diagnostic evaluation of precipitation in CORDEX models over southern Africa. Journal of Climate 26: 9477-9506.

Liebmann B, Camargo SJ, Seth A, Marengo JA, Carvalho LMV, Allured D, Fu R, Vera CS. 2007. Onset and end of the rainy season in South America in observations and the ECHAM 4.5 atmospheric general circulation model. Journal of Climate 20: 2037-2050.

Nikulin G, Jones C, Giorgi F, Asrar G, Büchner M, Cerezo-Mota R, Christensen OB, Déqué M, Fernandez J, Hänsler A, van Meijgaard E, Samuelsson P, Sylla MB, Sushamak L. 2012. Precipitation climatology in an ensemble of CORDEX-Africa regional climate simulations. Journal of Climate 25: 6057-6078.

Perkins SE, Pitman AJ, Holbrook NJ, Macaneney J. 2007. Evaluation of the AR4 climate models' simulated daily maximum temperature, minimum temperature, and precipitation over Australia using probability density functions. Journal of Climate 20: 4356-4376.

Rauscher SA, Seth A, Liebmann B, Qian J-H, Camargo SJ. 2007. Regional climate model simulated timing and character of seasonal rains in South America. Monthly Weather Review 135: 2642-2657.

Reason CJC, Hachigonta S, Phaladi RF. 2005. Interannual variability in rainy season characteristics over the Limpopo region of southern Africa. International Journal of Climatology 25: 1835-1853.

Rocha A, Simmonds I. 1997. Interannual variability of south-eastern African summer rainfall. Part 1: relationships with air-seas interaction processes. International Journal of Climatology 17: 235-265.

Ropelewski CF, Halpert MS. 1987. Global and regional scale precipitation patterns associated with the El Niño/Southern Oscillation. Monthly Weather Review 115: 1606-1626.

Seneviratne S, Nicholls N, Easterling D, Goodess CM, Kanae S, Kossin J, Luo Y, Marengo J, McInnes K, Rahimi M, Reichstein M, Sorteberg A, Vera C, Zhan X. 2012. Changes in climate extremes and their impacts on the natural physical environment. In Managing the Risks of Extreme Events and Disasters to Advance Climate Change Adaptation (SREX). Special Report of the Intergovernmental Panel on Climate Change (IPCC), Field CB, Barros V, Stocker TF, Dahe Q (eds). Cambridge University Press: Cambridge, UK and New York, NY; 109-230.

Shongwe ME, van Oldenborgh GJ, van den Hurk BJJM, de Boer B, Coelho CAS, van Aalst MK. 2009. Projected changes in mean and extreme precipitation in Africa under global warming. Part I: southern Africa. Journal of Climate 22: 3819-3837.

Simmons A, Uppala S, Dee D, Kobayashi S. 2006. ERA-Interim: new ECMWF reanalysis products from 1989 onwards. ECMWF Newsletter 110: $25-35$.

Sylla MB, Giorgi F, Coppola E, Mariotti L. 2013. Uncertainties in daily rainfall over Africa: assessment of gridded observation products and evaluation of a regional climate model simulation. International Journal of Climatology 33: 1805-1817. 
Tadross MA, Hewitson BC, Usman MT. 2005. The interannual variability of the onset of the maize growing season over South Africa and Zimbabwe. Journal of Climate 18: 3356-3372.

Tadross M, Suarez P, Lotsch A, Hachigonta S, Mdoka M, Unganai L, Lucio F, Kamdonyo D, Muchinda M. 2009. Growing-season rainfall and scenarios of future change in southeast Africa: implications for cultivating maize. Climate Research 40: 147-161.

Taylor KE. 2001. Summarizing multiple aspects of model performance in a single diagram. Journal of Geophysical Research 106 $7183-7192$.
Trenberth KE. 1999. Atmospheric moisture recycling: role of advection and local evaporation. Journal of Climate 12: 1368-1381.

Trenberth KE, Dai A, Rasmussen RM, Parsons DB. 2003. The changing character of precipitation. Bulletin of the American Meteorological Society 84: 1205-1217.

Tyson PD, Preston-Whyte RA. 2000. The Weather and Climate of Southern Africa. Oxford University Press: Cape Town, South Africa; 396 pp. 